\title{
OS IMPRESSOS ESTUDANTIS E A HISTÓRIA DA EDUCAÇÃ̃
}

\author{
Carla Michele Ramos Torres ${ }^{1}$ \\ Maria Isabel Moura Nascimento ${ }^{2}$
}

\section{Resumo}

O artigo apresenta os resultados do estado da arte da pesquisa de doutorado História, Educação e Imprensa Estudantil: o pensamento progressista na revista Movimento da UNE, 1962-1963. O objetivo é demonstrar como a história da educação brasileira pela imprensa estudantil foi abordada nas produções acadêmicas stricto sensu dos Programas de PósGraduação em Educação do Brasil, tendo como ponto de partida os estudos que possuem como fonte primária ou objeto de investigação a imprensa estudantil. O levantamento permitiu mapear treze dissertações, a maioria sob o viés da história cultural, revelando uma carência de trabalhos fundamentados no materialismo histórico dialético, bem como o ineditismo da pesquisa doutoral em construção.

Palavras-chave: História da educação. Imprensa estudantil. Materialismo histórico dialético.

\section{THE STUDENT PRESS AND THE HISTORY OF EDUCATION}

\begin{abstract}
This paper presents the state of the art results from the doctoral search History, Education and Student Press: the progressive thought in the UNE's Movimento magazine, 1962-1963. Its goal is to demonstrate how the history of Brazilian education through the student press is being addressed in academic literature in Education stricto sensu postgraduate programs in Brazil, having as its starting point the studies that have as a primary source or object the investigation of the student press. The survey allowed map thirteen dissertations, where most of them are grounded in cultural history, thus revealing the lack of substantiated research in the dialectical historical materialism, as well as the originality of the doctoral research in construction.
\end{abstract}

Keywords: History of education. Student press. Dialectical historical materialism.

\section{LOS IMPRESOS ESTUDIANTILES Y LA HISTORIA DE LA EDUCACIÓN}


doi: $10.20396 /$ rho.v18i2.8651230

\section{Resumen}

El artículo presenta los resultados del estado del arte de la investigación de doctorado Historia, Educación y Prensa Estudiantil: el pensamiento progresista en la revista Movimiento de la UNE, 1962-1963. El objetivo es demostrar cómo la historia de la educación brasileña por la prensa estudiantil fue abordada en las producciones académicas stricto sensu de los Programas de Postgrado en Educación del Brasil, tomando como base los estudios que poseen como fuente primaria u objeto de investigación la prensa estudiantil. El levantamiento permitió mapear trece disertaciones, la mayoría bajo el sesgo de la historia cultural, revelando una carencia de trabajos fundamentados en el materialismo histórico dialéctico, así como el carácter inédito de la investigación doctoral en construcción.

Palabras clave: Historia de la educación. Prensa estudiantil. Materialismo histórico dialéctico.

\section{INTRODUÇÃO}

A História, enquanto ciência humana, e consequentemente o ofício do historiador vem passando por profundas transformações desde 1930. A Escola dos Annales ${ }^{3}$ problematizou a historiografia e buscou a partir da integração com outras ciências avançar do campo político para outras dimensões sociais. Assim, no decorrer do século XX os historiadores ampliaram suas temáticas de estudos e suscitaram sujeitos históricos, antes negligenciados pela historiografia positivista ${ }^{4}$. Dessa maneira, diferentes vestígios e métodos foram explorados pelos estudiosos, colaborando para uma maior diversificação das pesquisas históricas. Sabe-se que a escrita da História se faz com fontes, porém, é preciso tomar cuidado para não utilizá-las como verdades em si e sim historicizá-las em harmonia com o objeto de pesquisa. Para Dermeval Saviani (2004, p. 5):

\footnotetext{
As fontes estão na origem, constituem o ponto de partida, a base, o ponto de apoio da construção historiográfica que é a reconstrução, no plano do conhecimento, do objeto histórico estudado. Assim, as fontes históricas não são a fonte da história, ou seja, não é delas que brota e flui a história. Elas, enquanto registros, enquanto testemunhos dos atos históricos, são a fonte do nosso conhecimento histórico, isto é, é delas que brota, é nelas que se apoia o conhecimento que produzimos a respeito da história.
}

As fontes históricas direcionam o investigador para um determinado objeto, num dado espaço temporal, e este ao situar-se diante disto pretende ser membro de uma comunidade, pois, o "[...] passado é, portanto, uma dimensão permanente da consciência humana, um componente inevitável das instituições, valores e outros padrões da sociedade humana." (HOBSBAWM, 1998, p. 22). Portanto, as contradições do tempo presente levam o historiador a inclinar-se para um instante do passado na busca de analisar a relação do 
Artigo

doi: $10.20396 /$ rho.v18i2.8651230

ontem e do hoje e identificar as transformações ocorridas. Além disso, a própria seleção do objeto de pesquisa demonstra o arcabouço teórico no qual o pesquisador está inserido.

Conforme a concepção marxiana ${ }^{5}$, o objeto de pesquisa existe objetivamente, ou seja, sua existência independe da consciência do investigador. Porém, cabe ao historiador, por exemplo, captar a estrutura e a dinâmica desse objeto, enquanto processo, buscando ir além da aparência e apoderando-se da matéria em seus detalhes, analisando suas variadas formas de desenvolvimento e examinando a conexão entre elas, uma vez que só depois desse procedimento é que ocorre a exposição adequada do movimento real do objeto. (MARX, 1843).

A investigação histórica sob o referencial teórico-metodológico do materialismo histórico dialético nos desafia a desvendar a base material que se assenta o objeto. Por materialidade, podemos definir as conjunturas históricas, políticas, econômicas e sociais nas quais os indivíduos estão submetidos, considerando desta maneira os homens em seu contexto social, em suas reais condições de vida, pois destas circunstâncias é que resulta o que os homens são. (MARX; ENGELS, 2007). Ao desviar-se disso, a pesquisa torna-se limitada à interpretação do mundo, o que para Marx não basta, pois é preciso transformá-lo, como apontou na décima primeira tese sobre Feuerbach.

A pesquisa de doutorado intitulada História, Educação e Imprensa Estudantil: o pensamento progressista na revista Movimento da UNE, 1962-636 visa analisar as ideias definidas como progressistas no periódico Movimento, considerando as condições materiais dos estudantes universitários brasileiros no período em que a União Nacional dos Estudantes (UNE) publicou onze edições desse impresso. Sendo o objeto de estudo a ideologia ${ }^{7}$, presente no impresso citado, cabe ressaltar que a imprensa é considerada, na pesquisa citada, como pensamento de uma época, portanto, é por meio do periódico que a entidade estudantil difundiu suas concepções políticas, econômicas, sociais e culturais. Como fonte histórica, o conteúdo da revista não será apoderado como verdade absoluta, mas sim como um dos elementos de um todo concreto em que há múltiplas relações de reciprocidade e contradições, seguindo os pressupostos do materialismo histórico dialético.

Nas últimas décadas estão em ascensão os estudos na área da História da Educação Brasileira que utilizam como fontes primárias e/ou objetos de análise os periódicos. Além do mais, não é somente a imprensa de educação e de ensino ${ }^{8}$ que está na pauta dos pesquisadores, mas também a imprensa ligada às instituições e organizações políticas e sociais direcionadas aos diversos públicos. Para Toledo e Skalinski Junior (2012, p. 265), os periódicos "[...] que se ocupem de notícias gerais podem, perfeitamente, ser fontes para pesquisas em História da Educação, na medida em que os debates relativos à educação costumam encontrar nesta mídia um caminho para atingir amplos setores da população." Sobre a relevância de periódicos como fonte histórica, Renée Zicman destacou que a imprensa "[...] é rica em dados e elementos, e para alguns períodos é a única fonte de 
Artigo

doi: $10.20396 /$ rho.v18i2.8651230

reconstituição histórica, permitindo um melhor conhecimento das sociedades ao nível de suas condições de vida, manifestações culturais e políticas, etc." (1985, p. 90 apud OLIVEIRA, 2011, p. 128).

No intuito de justificar o ineditismo da tese em desenvolvimento no Programa de Pós-Graduação em Educação da Universidade Estadual de Ponta Grossa na linha de pesquisa História e Política Educacionais, ênfase na História da Educação, procurou identificar as lacunas presentes no conjunto de produções acadêmicas brasileiras, nível mestrado e doutorado, na área de Educação, no que tange ao tema central da pesquisa de doutorado citado. Portanto, este artigo visa apresentar o resultado do estado da arte, finalizado em novembro de 2016.

Os procedimentos metodológicos adotados consistiram: a) pesquisa por meio do Banco de Teses e Dissertações dos Programas Brasileiros de Pós-Graduação Stricto Sensu em Educação ${ }^{9}$, cuja área de concentração do Programa é Educação; b) seleção de produções a partir das palavras-chaves: ideias progressistas, União Nacional dos Estudantes, imprensa estudantil, revista Movimento; c) leitura dos resumos das produções encontradas; d) mapeamento dos estudos que possuíam como temática o campo das ideias e a imprensa estudantil, sendo suas fontes primárias e/ou objetos de investigação os impressos estudantis ${ }^{10}$.

A partir dos critérios estabelecidos, o levantamento obteve como resultado a seleção de treze produções, sendo todas dissertações. Verificou-se que a história da educação pela imprensa estudantil, sob o viés teórico-metodológico do materialismo histórico dialético é um campo de pesquisa bastante frutífero a ser investigado, pois, somente uma dissertação, utilizou esse referencial. $\mathrm{O}$ estado da arte também revelou que a maioria das produções selecionadas partiu dos pressupostos teóricos da História Cultural, ao valorizar a escrita e a leitura como práticas socioculturais. Em outros estudos o foco foram as ações e concepções dos estudantes ligados ao movimento estudantil, logo os impressos se tornaram fontes privilegiadas para as análises históricas dessas agremiações políticas estudantis.

Devido ao fato, de ter sido constatado, durante o mapeamento, de que há certa unidade entre algumas dissertações em relação às abordagens teóricas, assuntos e emprego de fontes, as mesmas serão apresentadas por afinidades teóricas e temáticas e não por ano de conclusão ou grau de importância. Pretende-se, portanto, demonstrar como a imprensa estudantil, seja como fonte ou objeto de investigação, vem sendo abordada por pesquisadores da área da educação em suas produções acadêmicas stricto sensu e também contrastá-las com o projeto de pesquisa doutoral citado, fundamentado no materialismo histórico dialético.

\section{MOVIMENTO ESTUDANTIL E SUA IMPRENSA}


Segundo Nelson Werneck Sodré (1977, p. 01) a "[...] ligação dialética é facilmente perceptível pela constatação da influência que a difusão impressa exerce sobre o comportamento das massas e dos indivíduos." Mas se por um lado, a imprensa interfere nas ações dos sujeitos, é fundamental considerar que são os indivíduos os produtores das ideias e estes as produzem a partir de suas condições materiais, ou seja, de seu processo de vida real. (MARX, ENGELS, 2007). Portanto, a imprensa na pesquisa de doutorado História, Educação e Imprensa Estudantil: o pensamento progressista na revista Movimento da UNE, 1962-63 é a expressão das concepções dos sujeitos ligados à entidade estudantil e nesse sentido ao partir dos pressupostos de Karl Marx e Friedrich Engels é necessário contextualizar esses sujeitos no seu tempo e espaço, em especial no que diz respeito à atuação desses estudantes no modo de produção capitalista e posteriormente compreender as ideias disseminadas pelo periódico.

A análise das produções acadêmicas que tem como temática central o movimento estudantil e como fontes primárias os periódicos estudantis pode revelar como os pesquisadores da educação, vem discutindo ao longo das últimas décadas essa temática e as abordagens teóricas nas quais estão alicerçados esses estudos acadêmicos.

Na dissertação $O$ Diálogo é a violência: movimento estudantil e ditadura militar em 1968, defendida em 1997, Maria Ribeiro do Valle procurou observar a complexidade de percepções em torno da violência no movimento estudantil em 1968. A pesquisadora analisou os discursos e as ações desse movimento, do governo e da imprensa daquele período, que segundo ela foram atores centrais do cenário de violência vivenciado naquele contexto. Além de valer-se dos jornais da chamada grande imprensa, alguns favoráveis a mobilização estudantil e outros contrários, a pesquisadora fez uso de sete periódicos estudantis ${ }^{11}$.

O entendimento da autora em relação à imprensa enquanto ator no contexto de 1968 está baseado na seleção de periódicos considerados significativos na veiculação da temática violência, tanto por causa desses impressos se posicionarem diante dos protestos estudantis, quanto ao fato de interferirem num processo político mais amplo. Nesse sentido, defendeu que a "[...] análise da imprensa do movimento estudantil proporciona um rastreamento das definições e redefinições do seu papel, suas táticas e estratégias, a partir da própria dinâmica dos acontecimentos na conjuntura de 1968." (VALLE, 1997, p. VIII).

Na dissertação, Valle construiu uma abordagem acerca do movimento estudantil e da repressão aos estudantes nos anos ditatoriais partindo dos estudos de Poerner, Martins Filho, Gorender, Ventura, Moraes, Coelho e Ridenti ${ }^{12}$. Essas obras são referências para qualquer estudo que objetiva a reconstrução da história do movimento estudantil na República Brasileira, principalmente, nas campanhas travadas por estudantes e governo em tempos ditatoriais. 
Artigo

doi: $10.20396 /$ rho.v18i2.8651230

Ao utilizar impressos estudantis, Maria do Valle resgatou vários acontecimentos que marcaram o ano de 1968, como a morte do estudante Edson Luís (28/03/1968), a Sexta-Feira Sangrenta (26/06/1968), a Passeata dos Cem Mil (26/06/1968), a Guerra da Maria Antônia (iniciada em 02/10/1968) e o XXX Congresso da UNE (iniciado em 11/10/1968). Para a autora todos esses fatos registram que o "diálogo é a violência" quando se estuda a atuação do movimento estudantil no Brasil nesse período. Os periódicos estudantis, além de apresentar os fatos, evidenciaram o papel do estudante na tentativa de derrubar o governo militar e no processo de conscientização dos jovens acerca da necessidade de se manterem unidos nessa empreitada. A análise da autora se pautou em impressos de agremiações estudantis e bibliografias que exaltam a vanguarda dos estudantes nos processos de reforma e revolução, logo, esses periódicos podem ser identificados como instrumentos de militância política na conjuntura citada.

As matérias selecionadas e citadas na dissertação veem de encontro com a temática central do estudo, ou seja, a violência, no sentido de demonstrar o seu uso como prática legitimadora tanto por parte do governo, como pelos estudantes numa relação de enfrentamento entre civis e militares no final da década de 1960. Logo, Maria Ribeiro do Valle se apropriou da imprensa estudantil a fim de refletir a violência no cenário de tensões políticas experimentadas pelos grupos de oposição à ditadura militar, enfatizando a imprensa não só como fonte de informações, mas também como personagem ativa na propagação dessa concepção de mundo.

Os estudos que tem como foco os sujeitos estudantis, suas ações e ideologias, geralmente possuem entre suas fontes primárias registros históricos construídos por estes indivíduos. Nesse sentido, encontra-se a dissertação Em cena, o movimento estudantil acadêmico no Maranhão: 1930-1950 de Márcia Cordeiro Costa. Nesse estudo, a autora utilizou jornais universitários de instituições maranhenses para resgatar a história do movimento estudantil e contribuir para uma historiografia da educação superior brasileira, com enfoque nos sujeitos acadêmicos.

Segundo Costa (2009, p. 20), a imprensa é um “[...] espaço de lugares de memória, de exercício de identidade e de arquivamento do nosso tempo.” Logo, afirmou que por meio dela se produz conhecimento histórico, pois os conteúdos presentes nos jornais e revistas revelam o contexto no qual foram construídos. Para a autora, os impressos estudantis, especialmente, referenciam a educação e dessa maneira tornaram-se fontes para identificar as ideias e ações do movimento estudantil universitário maranhense, durante o processo de ampliação da educação superior no Brasil.

Os periódicos analisados na pesquisa são impressos de agremiações representativas dos acadêmicos de Direito da região maranhense. São eles: Folha Acadêmica (1934), Esquerda (1934), Voz Universitária (1954), Universitário em Marcha (1955), Vigilância (1957), Movimento (1958) e Universitário (1958). Segundo Costa, como foram encontradas 
Artigo

doi: $10.20396 /$ rho.v18i2.8651230

poucas edições desses jornais, optou-se por realizar entrevistas no início da pesquisa, algo que não se concretizou por vários motivos relatados na dissertação. A metodologia empregada no estudo é assim descrita:

\begin{abstract}
Inicialmente, como primeiro objetivo específico, mapeou-se o conjunto de exemplares identificando a designação do jornal, o ano, o número, a data, o vínculo com o Movimento Estudantil e respectiva presidência em exercício, os títulos das matérias e a publicidade veiculada.

A segunda fase da análise contemplou o conteúdo das matérias, incluindo a categorização, estipuladas a partir de um estudo prévio da documentação escrita e das inquietações iniciais do pesquisador conforme a temática contemplada São elas: (a) o Movimento Estudantil, (b) os estudantes, (c) o ensino superior, (d) as faculdades e sua organização. Simultaneamente a esta fase da pesquisa, realizouse a pesquisa bibliográfica sobre a temática abordada na qual imergimos em leitura e fichamentos do material documental. (COSTA, 2009, p. 23-24).
\end{abstract}

Verifica-se que os impressos foram descritos materialmente, ou seja, suas especificidades como tamanho, editores e financiadores. Além dos conteúdos analisados sobre as práticas de estudantes universitários e suas ideias, o estudo também buscou revelar o contexto político dos jovens que estavam à frente da direção desse meio de comunicação, bem como os autores das matérias. Para Costa (2009, p. 98-99), a história da educação pela imprensa permite recuperar as histórias e memórias dos acadêmicos, como autores sociais na construção do ensino superior no Maranhão, evidenciando “[...] os vestígios de um tempo e de um lugar, o modo de ver e pensar educação numa postura política, cultural e social." A contribuição de estudos a partir de fontes impressas, no campo da História da Educação, foi apontada como valorosa pelo número de informações vinculadas e seu caráter contestatório, pela atualidade dos fatos abordados e finalmente devido a sua função interventora.

Outra dissertação selecionada foi a do historiador Geenes Alves da Silva, devido ao fato de este anunciar na introdução do seu trabalho que pretendia utilizar exemplares de periódicos publicados por grêmios escolares para analisar o movimento estudantil em Patos de Minas. Porém, ao verificar atentamente seu estudo, intitulado A união dos estudantes secundaristas de Patos de Minas (UEP/MG): militância e formação cidadã e políticopartidária (1958 a 1971), percebe-se que os impressos estudantis ${ }^{13}$ foram elencados numa tabela e não foram explorados enquanto vestígios das atividades e ideologias dos estudantes secundaristas patenses. Sua pesquisa se embasou nos estudos de Poerner, Sanfelice, Foracchi e Ventura, e a fim de corroborar para uma escrita sobre o movimento estudantil, o pesquisador compreendeu a juventude a partir da teoria do pensador educacional Pierre Furter. Para Geenes Silva (2009), a juventude representa a fase entre a adolescência e a idade adulta e, embora, a consciência coletiva tenha sua origem na adolescência, a juventude não foi considerada classe.

Segundo Geenes Silva (2009, p. 52), os impressos produzidos pelos estudantes patenses, nas décadas entre 1930 e 1970, demonstraram “[...] empreendedorismo e aspiração 
à intelectualidade" e suas atividades, através de agremiações escolares, expressaram parte de suas histórias. Entre os resultados, o autor destacou que a União Estudantil Patense foi bastante influenciada por princípios cristãos e seus dirigentes provinham majoritariamente da elite local, o que fez dela uma entidade tradicionalista e conservadora.

Em relação a esta dissertação, acredita-se que os periódicos estudantis, se analisados na íntegra, poderiam revelar não só unidade entre os diversos grupos estudantis, mas também algumas contradições, pois, no materialismo histórico dialético compreende os impressos como expressões desses sujeitos agindo na sociedade coletivamente. Esse apontamento se justifica, devido ao fato do historiador centralizar suas afirmativas nas informações da Folha Diocesana, publicação dirigida por padres que se identificavam com as causas dos estudantes de Patos de Minas e que oportunizou uma coluna aos jovens estudantes intitulada Observatório Estudantil. Logo, esse jornal católico catalisou os ideais estudantis que melhor se ajustavam aos seus valores políticos, sociais e culturais, não se apoderando exclusivamente do pensamento estudantil.

Corroborando com estudos sobre organização política estudantil, Isaura Melo Franco procurou resgatar a história dos estudantes em Ituiutaba-MG, vinculados às agremiações estudantis, entre os anos de 1952 e 1968. Sua dissertação, Estudantes Tijucanos em cena: história de suas organizações políticas e culturais (Ituiutaba-MG, 1952-1968), teve como referências as obras de Poerner e Sanfelice, no que diz respeito ao movimento estudantil, bem como as contribuições de José Willington Germano, Luiz Antônio Cunha e Moacyr de Góes, em relação as políticas educacionais no período do governo militar brasileiro. Conceitos de juventude, movimento estudantil, cultura escolar e ditadura militar também foram explorados à luz das contribuições teórico-metodológicas da História Social, Política e Cultural no âmbito da História da Educação.

Nesse trabalho acadêmico, Franco partiu do princípio de que a história social e a história cultural devem caminhar juntas nos estudos historiográficos. Entre suas principais fontes estão os impressos comerciais e dois jornais estudantis locais: $O$ Vencedor, órgão do Grêmio estudantil do Instituto Marden e o impresso Sentinela do Estudante, porta-voz do Colégio São José e Escola Normal Santa Teresa. Em relação ao último jornal, a autora destacou que o periódico expressa a comunicação entre os estudantes das duas instituições de ensino citadas, principalmente em relação à defesa de valores culturais cristãos difundidos nesses estabelecimentos educacionais ligados às irmandades católicas. Já o impresso $O$ Vencedor, editorial de responsabilidade estudantil, mas com supervisão de um professor do Instituto Marden, apresentava poemas, crônicas, artigos e colunas de fofocas fundamentados em princípios cristãos, na valorização da disciplina, no patriotismo e patriarcalismo, sendo seus temas variados, desde questões sentimentais até de ordem cultural e social da época.

Para a pesquisadora, esses impressos estimularam a produção artística literária dos estudantes e permitiram a disseminação de ideais comungados pelas escolas frequentadas 


\section{Revista HIISTESIDBR On-lime}

Artigo

doi: $10.20396 /$ rho.v18i2.8651230

por esses jovens. Conceituando os jornais como ferramentas de transmissão e formação de ideias o estudo concluiu " [...] que estudar as práticas culturais dos estudantes em Ituiutaba norteia a compreensão não apenas de uma realidade específica, particular, mas de um contexto cultural e educacional de uma época." (FRANCO, 2014, p. 166). Por meio da análise dos conteúdos dos dois jornais estudantis e da sua nomenclatura, a investigação resgatou a história do movimento estudantil da cidade mineira de Ituiutaba, permitindo observar as particularidades de regiões interioranas do Brasil em relação ao processo de mobilização estudantil em nível nacional, durante as décadas de 1950 e 1960.

Das dissertações selecionadas, a produção intitulada A UNE e os partidos políticos no Governo Lula (2003-2010) de Gabriel Paiva foi escolhida por compor os estudos sobre movimento estudantil, a partir das leituras de Poerner, Sanfelice e Martins Filho, e adotar como uma de suas fontes primárias a revista Movimento, fonte esta da pesquisa de doutorado mencionada no início deste artigo, embora as edições sejam de contextos diferentes. $\mathrm{O}$ historiador buscou analisar a relação da UNE com o governo do presidente Luís Inácio Lula da Silva e a atuação dos diversos partidos políticos no interior desta entidade estudantil a partir das categorias independência política e democracia. A primeira categoria concebeu independência política como a autonomia dos movimentos estudantis diante do Estado e partidos políticos, principalmente no aspecto financeiro; enquanto a categoria democracia definiu-se como deliberação da base do movimento estudantil, por meio de congressos e assembleias, acima do pleito da diretoria.

As reportagens do periódico Movimento, selecionadas por Paiva foram àquelas publicadas entre os anos de 2004 e 2008 pela UNE e que se relacionavam com o tema educação e com o governo daquele período. A escolha foi justificada pelo fato do período coincidir com o mandato presidencial de Lula, contexto este de campanhas em prol de uma reforma universitária com conteúdo democrático, por parte da entidade estudantil. Por meio das matérias dessa revista o autor evidenciou o vínculo de colaboração e negociação entre a entidade estudantil e o governo petista no que diz respeito às políticas educacionais desse governo como, por exemplo, o Programa de Reestruturação das Universidades Federais (REUNI) e o Programa Universidade para Todos (PROUNI).

Na dissertação, Paiva utilizou a revista somente para extrair dela as concepções acerca da Reforma Universitária defendidas pela UNE durante o governo Lula e as políticas educacionais durante esse período. Para o pesquisador as matérias manifestavam certo apoio da agremiação à plataforma política petista. Além desse periódico, o autor também utilizou o Jornal da UNE, edições de 2006 e 2007, com ênfase nos textos de Gustavo Petta, presidente da entidade estudantil, e seus apontamentos sobre o projeto de reforma universitária encaminhado ao congresso. Se os conteúdos dos dois impressos fossem contrastados, o que não ocorreu, a análise contribuiria para revelar ainda mais as dissidências no movimento estudantil e trazer à tona uma discussão, ainda muito incipiente nos estudos 
acadêmicos, acerca da imprensa estudantil como porta voz de uma entidade ou da fação política dos dirigentes desse mesmo grupo.

Os conteúdos desses impressos foram analisados pelo historiador a fim de privilegiar o discurso da entidade, todavia é necessário levar em consideração, ao trabalhar com fontes impressas, que a notícia ou reportagem além de ser expressão do seu tempo e espaço é também produção subjetiva. À vista disso, compactua-se da premência de ponderar a escrita impressa a partir da função social e política da entidade que a sustenta financeiramente, bem como dos autores dessa escrita, ligados à suas realidades materiais da qual faz emergir seus posicionamentos.

As cinco dissertações analisadas apresentaram como foco central o movimento estudantil, por isso entre as referências estão os estudos de Poerner, Sanfelice, Foracchi e Martins Filho. Além do mais, os periódicos foram utilizados como fontes de informação para contextualizar os discursos e as ações das agremiações políticas secundaristas e universitárias, tecendo desta maneira a história do movimento estudantil brasileiro. Porém, as análises contextualizaram brevemente as condições históricas nas quais estavam inseridos os estudantes brasileiros, uma vez que o materialismo histórico dialético não fez parte de seus pressupostos teóricos e metodológicos.

Segundo Marx e Engels (2007) a ideologia é apenas um dos lados da história humana. Logo, ao considerar a imprensa estudantil-universitária como ideologia e centrar-se nesta para reconstruir a história do movimento estudantil brasileiro tem-se como resultado uma reconstrução parcial dessa história. Por isso na tentativa de analisar o objeto em sua totalidade histórica a investigação fundamentada na teoria marxiana propõe observar os impressos dos estudantes a partir da base material de uma determinada sociedade, ou seja, expor as ideias a partir da realidade e não o contrário. Dessa maneira, é possível entender o movimento real da história humana e revelar as contradições no âmago das ideologias.

\section{HISTÓRIA DA CULTURA ESCRITA: OS PERIÓDICOS ESTUDANTIS}

A partir do levantamento das produções acadêmicas na área da Educação pela imprensa estudantil, foram selecionadas três dissertações construídas a partir da perspectiva da História da Cultura Escrita e da Leitura. Esses estudos provenientes da Universidade Federal do Rio Grande do Sul se pautaram em impressos de agremiações escolares e entidades políticas-sociais com foco no estudo da materialidade da revista ${ }^{14}$.

Na dissertação Hyloea: o feminino na revista dos alunos do Colégio Militar de Porto Alegre (1922-1938) ${ }^{15}$, Silvana Schuler Piñeda investigou as representações do universo feminino na revista Hyloea a partir dos textos e imagens presentes nesse periódico. Para isso 
fez uso da análise do discurso textual das matérias impressas, observando a materialidade e o ciclo de vida da revista.

Nesta mesma linha de pesquisa surgiu outra dissertação intitulada Imprensa Estudantil e Práticas de Escrita e de Leitura: a Revista O Estudo (Porto Alegre/RS, 1922 a 1931). O objeto de investigação foi um corpus documental composto de 31 exemplares da revista $O$ Estudo, publicada nas décadas de 1920 e 1930, pelo Grêmio de Estudantes da Escola Complementar/Normal de Porto Alegre. Sobre esse trabalho acadêmico, destaca-se que o objetivo foi compreender as práticas de escrita e leitura de alunas que pertenciam ao grêmio estudantil da instituição educacional citada. Portanto, os impressos foram compreendidos como "[...] práticas de escrita e de leitura das alunas-autoras" (FRAGA, 2012, p. 23), revelando uma fração do cotidiano escolar segundo o ponto de vista das estudantes. Como produto da cultura escrita, conforme apontou a autora, o periódico $O$ Estudo define-se como um artefato sociocultural pela circulação de textos, bem como a assimilação de valores, métodos e práticas de ensino difundidas nas décadas de 1920 e 1930 no Brasil.

Na mesma direção, encontra-se a dissertação Psiu! Fermento! Pastoral da Juventude \& Imprensa Estudantil nos anos 1980 a 1990, de Patrícia Machado Vieira que também adotou os pressupostos teóricos da História Cultural e da História da Cultura Escrita. A produção investigou dois conjuntos de periódicos juvenis ligados à Pastoral da Juventude nas décadas finais do século XX e teve como objetivo identificar e compreender os processos que geraram a produção destes periódicos e sua função na formação de jovens estudantes secundaristas.

O periódico $P S I U$ era produzido pela Pastoral da Juventude Estudantil (PJE), em sua organização estadual do Rio Grande do Sul. Esse segmento da Igreja Católica “[...] se ocupa da tarefa de evangelizar e trabalhar com jovens estudantes em seu meio específico, a escola. Os grupos de jovens, as atividades e ações são desenvolvidas na e a partir da escola." (VIEIRA, 2014, p. 26). Já o periódico Fermento, era de responsabilidade da coordenação da Pastoral da Juventude (PJ) da Arquidiocese de Porto Alegre. Tanto a PJ como a PJE eram organizações católicas voltadas para o público juvenil, portanto em idade escolar. As informações apontaram os dois impressos como estudantis, por serem produções de jovens estudantes e por ser expressão de suas aspirações. Além disso, a autora chegou a afirmar que Psiu e o Fermento foram mais do que impressos estudantis de juventude, eram "compósitos" das experiências desses sujeitos.

Como o objeto de estudo foram os próprios impressos, Vieira realizou uma análise do conteúdo e da materialidade dos periódicos, enfatizando seus protocolos de leitura, ou seja, os mecanismos empregados intencionalmente a fim de assegurar uma leitura ideal do texto. Muitas reportagens e imagens foram apresentadas ao longo da dissertação, porém, uma contextualização histórica mais apurada daquelas ilustrações e mensagens não fez parte 
Artigo

doi: $10.20396 /$ rho.v18i2.8651230

do estudo. Mas o que difere a pesquisa de Vieira com as produções de Piñeda e Fraga é o fato de selecionar impressos que circularam em espaços de educação informal, no caso as pastorais católicas bastante atuantes no cenário político brasileiro naquele período.

Estudar a materialidade da revista tem como proposta a análise do texto escrito, o que no viés da História Cultural tem sua importância no sentido de refletir sobre as representações e as práticas sociais dos sujeitos escritores e leitores de tais periódicos. Essa abordagem se diferencia dos estudos que empregam o materialismo histórico dialético, uma vez que estes se fundamentam do seguinte princípio:

[...] não se parte daquilo que os homens dizem, imaginam ou representam, tampouco dos homens pensados, imaginados e representados para, a partir daí, chegar aos homens de carne e osso; parte-se dos homens realmente ativos e, a partir de seu processo de vida real, expõe-se também o desenvolvimento dos reflexos ideológicos e dos ecos desse processo de vida. (MARX; ENGELS, 2007, p. 94).

Logo, os estudos históricos da educação pela imprensa estudantil assentados no materialismo histórico dialético e na categoria de totalidade, permitem observar o objeto de investigação conectado com outros elementos pertencentes à vida material dos indivíduos, colaborando para uma análise não fragmentada do real, resistindo às produções idealistas e as concepções simplificadas e generalizadas.

Na sociedade capitalista os indivíduos estão divididos em classes antagônicas, sendo que nessa relação de forças contraditórias os dois principais polos são a burguesia e o proletariado. Nesse sentido, estudar os impressos estudantis sob o viés marxiano é primeiramente constatar que aquele que escreve ou que financia o periódico vivencia essa luta de classes e por isso é fundamental refletir criticamente, à luz dessa materialidade, os sujeitos e suas concepções.

\section{HISTÓRIA CULTURAL: EDUCAÇÃO E CULTURA NOS PERIÓDICOS ESTUDANTIS}

O estado da arte revelou que alguns estudos na área da Educação veem empregando a imprensa estudantil como fonte primária para analisar diferentes objetos relacionados ao contexto educacional e cultural brasileiro. Nessas pesquisas, a História Cultural, em especial os conceitos de Roger Chartier e Michel de Certeau encontraram amplo espaço de discussão.

Na dissertação Traço de União como Vitrine: educação feminina, ideário católico e práticas escolanovistas no periódico do Colégio Jacobina, a autora buscou examinar os discursos publicados na revista Traço de União como produtos e produtores de significados. Esse periódico circulou entre os anos de 1908 e 1981 e "[...] constituiu-se um espaço privilegiado para disseminação de um modelo de educação feminina, do ideário católico e 
doi: $10.20396 /$ rho.v18i2.8651230

de práticas pedagógicas inovadoras." (CARUSO, 2006, p. 08). A materialidade da revista foi privilegiada, bem como a biografia de suas responsáveis e por fim a análise de temas nas páginas dos impressos, como por exemplo, o papel social da mulher na construção da nação, mulher e trabalho, escola e família, educação feminina e católica.

O estudo de Andrea Caruso faz parte dos trabalhos desenvolvidos no âmbito da história da educação brasileira pela imprensa estudantil católica feminina. Em relação aos conceitos de Chartier, a autora destacou o de representações, que segundo ela estava presente nesses escritos femininos, permitindo verificar os interesses impositivos e contraditórios por trás desses discursos. Para compreender as biografias das responsáveis pela revista, a autora valeu-se da noção de redes de pertencimento de Pierre Bourdieu.

Ainda no campo da história cultural, mais especificamente da Nova História Cultural, está a dissertação de Carla Zottolo Villanova Souza intitulada No mundo das normalistas: as representações da futura professora nas páginas das revistas Instituto e Normalista (1941-1953). A pesquisadora fez uso do pensamento de Michel de Certeau sobre a escrita da história, do conceito de instrumentos de controle de Michel Foucault e a concepção de mulher de Simone de Beauvoir. Seu objetivo foi refletir as representações relativas ao campo do magistério, tendo como foco a futura educadora brasileira nas décadas de 1940-1950. Para tal empreitada suas fontes primárias foram as revistas Instituto e Normalista do Instituto de Educação do Rio de Janeiro (IERJ), sendo somente o último periódico de caráter estudantil.

Essa produção acadêmica buscou identificar através da revista Normalista, produzida entre os anos de 1948 e 1953, pelas alunas do grêmio cultural Rui Barbosa do IERJ, elementos de permanência e rupturas dos valores religiosos e cívicos nos discursos e práticas de formação docente daquele período na instituição de ensino carioca. Ao abordar tais questões a pesquisadora contextualizou a política e a cultura brasileira, no sentido de revelar os desdobramentos no universo educacional, fazendo conexões entre as mudanças nas temáticas do periódico com as transformações no âmbito social. Dessa maneira, Normalista no entendimento da autora vinculou-se tanto ao pensamento da instituição educacional quanto aos anseios das futuras-professoras ali representadas.

Outro estudo sobre o viés da História Cultural é a dissertação A Configuração do habitus professoral para o aluno-mestre: a Escola Normal Secundária de São Carlos (19111923). Nesta, o objeto de pesquisa foi o campo educacional da Escola Normal Secundária de São Carlos, entre os anos de 1911 e 1923. Emerson Correia da Silva trabalhou com o conceito de campo e habitus do sociólogo francês Pierre Bourdieu e com a perspectiva da História Cultural de Roger Chartier. Para o autor, nesse campo de relações em que se encontram objetos de disputas o foco era a formação dos professores e os agentes envolvidos seriam os docentes, discentes e funcionários da instituição escolar, bem como representantes políticos ligados à educação pública. Para tal empreendimento, analisou dois periódicos, 


\section{Revista HIISTESIDBR On-lime}

Artigo

doi: $10.20396 /$ rho.v18i2.8651230

sendo um deles a revista Excelsior!, publicação do Grêmio Normalista "Vinte e Dois de Março".

O periódico estudantil citado foi considerado por Emerson Silva (2009) como imprensa educacional e sua análise privilegiou o ciclo de vida e a materialidade da revista. Essa dissertação foi selecionada, devido ao fato de Excelsior ser considerado impresso de um Grêmio Estudantil, mas é preciso tecer algumas considerações sobre as particularidades da revista e da agremiação que a dirigia. O grêmio Normalista "Vinte e Dois de Março" surgiu com a fundação da Escola Normal Secundária de São Carlos em 1911 e era basicamente uma organização literária e pedagógica formada por alunos, mas com forte dominação da direção e professores da instituição educacional. Salienta-se que essa realidade deve ser considerada na identificação de estudos historiográficos em educação pela imprensa estudantil.

E finalmente a produção acadêmica de Jaqueline Rampeloti Ozelin, denominada Periódicos Educacionais da Escola Normal de São Carlos: educação moral, civismo e higiene (1911-1923), que teve como principais fontes os impressos estudantis Excelsior! (1911-1916) e O Raio Verde (1917-1918). Por meio destes, a pesquisadora procurou observar como as temáticas de educação moral, civismo e higiene foram apropriadas pelos diferentes sujeitos da instituição escolar citada. Para fundamentar seu trabalho utilizou estudos vinculados ao seu objeto e como perspectiva teórica a História Cultural, com ênfase nos conceitos sobre produção, apropriação e representação elaborados por Roger Chartier.

Nessa investigação Ozelin contextualizou politicamente e economicamente a Primeira República antes de se debruçar nos periódicos, porém sem fazer relação direta com o modo de produção capitalista. Num segundo momento, se dedicou a materialidade dos impressos, para posteriormente focar em suas matérias. Os periódicos educacionais foram definidos como fontes de extrema importância, por serem pensamentos de uma época.

Comunga-se da concepção de que os impressos estudantis são ricas fontes históricas, porém é preciso ir além das aparências para captar um conjunto de ideias. Desse modo, é fundamental ir muito além da matéria escrita ou de um corpus documental impresso, uma vez que os pensamentos de uma época são produzidos pelos homens e estes são condicionados por um determinado nível de desenvolvimento de suas forças produtivas, segundo a concepção de Marx e Engels (2007). Por isso, essa realidade deve ser o ponto de partida das pesquisas que almejam ir além da interpretação histórica.

De maneira geral, os estudos a partir da perspectiva da História Cultural que tem como fonte primária e/ou objeto de investigação a imprensa estudantil nos programas brasileiros de pós-graduação em Educação estão centrados nas reflexões da cultura escolar, história da escrita, leitura e práticas escolares. Já em relação ao método, as pesquisas concentram seus esforços na análise dos conteúdos, da materialidade e do ciclo de vida dos 
Artigo

doi: $10.20396 /$ rho.v18i2.8651230

periódicos, sem muitas vezes relacionar a escrita com um universo mais amplo em suas dimensões culturais, políticas e econômicas.

Em outra direção caminham as investigações históricas alicerçadas no materialismo histórico dialético, pois estas procuram colaborar para desvendar a ideologia que sustenta o modo de produção vigente. Pois, sob o horizonte da práxis revolucionária pretende-se demonstrar através do conhecimento científico o processo de vida real dos seres humanos. E como fizeram Marx e Engels no século XIX, os pesquisadores de hoje podem utilizar de seu ofício para indicar o caminho para a emancipação humana ${ }^{16}$. Pois, segundo Lenine (1982, p. 39):

Só o materialismo filosófico de Marx indicou ao proletariado a saída da escravidão espiritual em que vegetaram até hoje todas as classes oprimidas. Só a teoria econômica de Marx explicou a situação real do proletariado no conjunto do regime capitalista.

\section{IMPRENSA ESTUDANTIL E MATERIALISMO HISTÓRICO DIALÉTICO}

Das dissertações selecionadas no estado da arte, o estudo intitulado A Educação do Corpo e o protagonismo discente no Colégio Pedro II: mediações entre o ideário republicano e a memória histórica da instituição (1889-1937) se diferenciou das demais por estar fundamentada no materialismo histórico dialético e na História Social. A partir dessas concepções a cultura foi compreendida como campo de lutas e arena das disputas de classes, conceito este do historiador Edward Thompson. O objetivo do pesquisador em investigar o cotidiano escolar do Colégio Pedro II e como a educação do corpo e o protagonismo discente estavam relacionados aos ideários republicanos, levou-o a prestigiar como fontes históricas os impressos Sciencias e Letras (1926 e 1927) e O ARAUTO (1931).

Por meio desses dois impressos estudantis, Marques resgatou a história da instituição educacional citada, identificando assuntos rotineiros ligados aos sujeitos que ali estavam diariamente. Além disso, dedicou uma seção na tentativa de compreender as culturas escolares e a formação estudantil à luz do ideal republicano e da educação do corpo. O autor inicialmente caracterizou o modo de produção capitalista para debater a relação entre trabalho e educação, mas ao longo da análise dos impressos se prendeu aos aspectos textuais da escrita periódica, sem fazer uma relação direta e concomitante entre os impressos e a realidade material brasileira.

No primeiro capítulo, Marques chegou a discorrer sobre os pressupostos da teoria marxista, mas na análise dos periódicos estudantis não trabalhou com as categorias do método, pautando-se na descrição dos conteúdos dos impressos. É extremamente importante considerar que na perspectiva materialista da história o objeto dever ser compreendido em suas múltiplas relações, uma vez que o propósito do pesquisador é a apreensão do real e a 
Artigo

doi: $10.20396 /$ rho.v18i2.8651230

sua transformação. Pois, "Se separadas da história real, essas abstrações não têm nenhum valor.” (MARX; ENGELS, 2007, p. 95).

Para Zanlorenzi (2014, p. 31), os estudos da história da educação fundamentados no materialismo histórico dialético, devem considerar que a ideologia "Não é uma representação imaginária desvinculada da realidade, ela se efetiva no interior das relações concretas." Como e por que os homens constroem essa ideologia, são questionamentos que podem ser respondidos se for levado em conta que a visão de mundo dos sujeitos e/ou grupos sociais é a expressão da vida real, ou seja, de sua atividade prática, numa relação com si e com os outros diante de uma conjuntura social.

Nesse sentido, a consciência advém do fato desses sujeitos coletivos pensarem a realidade a partir de sua posição, enquanto classe, frente ao seu papel social em determinadas condições impostas e suas mediações com outras classes. Por isso, a imprensa torna-se uma fonte histórica importante para analisar o homem em diferentes contextos sociais. Embora, seja necessária uma atenção especial, por parte do historiador, ao trabalhar com esses vestígios, como revelou Zanlorenzi (2010, p. 65):

Entretanto, é necessário que o pesquisador tenha conhecimento que a imprensa
escrita expressa o ponto de vista tendenciosamente daqueles que a produzem,
porém esse é o ponto que o pesquisador irá ampliar, pois não há uma disputa entre
o certo e o errado, mas sim o desvelar das ideologias presentes e a forma de
persuasão utilizada, para influir socialmente.

Com base na concepção de que o ponto inicial da análise histórica é a dimensão real dos seres humanos e não seu campo de ideias, o impresso enquanto pensamento de uma época torna-se objeto concreto e síntese de múltiplas determinações. As tensões, as relações de poder, as representações de interesses e as generalizações conceituais, disseminadas nos impressos, nada mais são que elementos objetivos, pois são expressões das condições materiais dos indivíduos em um determinado modo de vida.

O caminho a trilhar é um constante desafio ao pesquisador, visto que a proposta é estudar as ideias a partir da materialidade humana e não da materialidade da revista, embora, alguns de seus aspectos particulares devam ser considerados na análise, devido às contradições que neles existem. Além do mais, por entender que a base real da ideologia está nas relações dos homens em sociedade, esses estudos históricos partem do princípio de que é preciso ir além dos textos impressos e das biografias dos autores, examinando criticamente os interesses de classe daqueles que escreveram no impresso estudantil e dos patrocinadores da revista, bem como as mudanças nas forças produtivas e nas relações de trabalho que condicionavam a sociedade da época.

A pesquisa de doutorado História, Educação e Imprensa Estudantil: o pensamento progressista na revista Movimento da UNE, 1962-63, emprega os pressupostos teóricos metodológicos do materialismo histórico dialético e se propõe analisar as ideias progressistas 
doi: $10.20396 /$ rho.v18i2.8651230

brasileiras a partir de uma realidade concreta que se fez presente no Brasil de 1930 até 1964. Os conteúdos e o papel político do periódico serão examinados à luz do comportamento material dos estudantes ligados à União Nacional dos Estudantes, entidade responsável pela produção do impresso Movimento, bem como das contradições do modo capitalista de produção. Dessa forma, pretende-se contribuir no âmbito da história da educação na república brasileira, da historiografia pela imprensa estudantil e dos estudos sob o viés materialista no campo do pensamento educacional.

\section{CONSIDERAÇÕES FINAIS}

O estado da arte realizado para justificar o ineditismo do projeto de pesquisa doutoral em desenvolvimento, História, Educação e Imprensa Estudantil: o pensamento progressista na revista Movimento da UNE, 1962-63, revelou que nos programas brasileiros de pósgraduação em Educação, de nível stricto sensu, há uma carência de pesquisas acerca da história da educação pela imprensa estudantil, sob o viés teórico-metodológico do materialismo histórico dialético. Esse dado justifica-se pelo fato de que no levantamento realizado não foi encontrado nenhuma tese e das treze dissertações selecionadas, somente uma produção empregou esse referencial.

Além disso, constatou-se que a maioria das produções partiu dos fundamentos teóricos da História Cultural, conceituando a escrita e a leitura como práticas socioculturais, bem como propôs resgatar a história do movimento estudantil tendo como fonte primária os impressos estudantis. Por fim, também salienta o fato de que não foi encontrado nenhum estudo acerca do pensamento progressista brasileiro na revista Movimento da UNE, objeto de estudo da pesquisa de doutorado citada.

Sendo uma abastada fonte de dados, a imprensa é considerada na investigação histórica em elaboração, a expressão do pensamento de uma determinada época. Logo, segundo o materialismo histórico dialético, é preciso partir das ações dos indivíduos reais, pois os homens não são seus pensamentos e sim seu processo de vida material. Escrever a história da educação pela imprensa periódica tendo como fundamentação esses princípios é ir além do registro dos fatos, não se preocupando com uma descrição centrada na materialidade e no ciclo do periódico, embora alguns apontamentos sejam necessários no decorrer da pesquisa.

Consequentemente, pretende-se apreender esse pensamento enquanto processo, observando sua gênese, seus elementos conceituais e sua dinâmica num dado período histórico, no sentido de compreender as práticas e as ideologias dos estudantes numa realidade concreta, em movimento e influenciada pelas condições materiais de produção humana. Ao contrário das pesquisas já realizadas no campo da história da educação quem tem como fonte ou objeto a imprensa estudantil, o estudo científico, cuja, a temática central 
Artigo

doi: $10.20396 /$ rho.v18i2.8651230

é o pensamento progressista na revista Movimento, intenciona revelar que são os homens os produtores das ideias e esses mesmos homens possuem essas ideias por estarem condicionados num nível de desenvolvimento de suas forças produtivas. Logo, essa materialidade precisa ser o ponto de partida para compreender a imprensa periódica e não o inverso.

\section{REFERÊNCIAS}

CARUSO, A. Traço de união como vitrine: educação feminina, ideário católico e práticas escolanovistas no periódico do Colégio Jacobina. Dissertação (Mestrado em Educação) - Universidade do Estado do Rio de Janeiro, Rio de Janeiro, 2006.

CATANI, D.; BASTOS, M. H. C. (Org.). Educação em revista. A imprensa pedagógica e a história da educação. São Paulo: Escrituras, 1997.

COSTA, M. C. Em cena, o movimento estudantil acadêmico no Maranhão: 1930-1950. 2009. Dissertação (Mestrado em Educação) - Universidade Federal do Maranhão, São Luís, 2009.

FRAGA, A. S. Imprensa estudantil e práticas de escrita e de leitura: a revista o estudo (Porto Alegre/RS, 1922 a 1931). 2012. Dissertação (Mestrado em Educação) Universidade Federal do Rio Grande do Sul, Porto Alegre, 2012.

FRANCO, I. M. Estudantes Tijucanos em cena: história de suas organizações políticas e culturais (Ituiutaba-MG, 1952-1968). 2014. Dissertação (Mestrado em Educação) Universidade Federal de Uberlândia, Uberlândia, 2014.

HOBSBAWM, E. Sobre História. São Paulo: Companhia das Letras, 1998.

LENINE, V. I. As três fontes e as três partes constitutivas do marxismo. In: LENINE, V. I. Obras escolhidas. 2. ed. São Paulo: Alfa-Omega, 1982. p. 35-39. v. 1.

MARQUES, G. R. D. A educação do corpo e o protagonismo discente no Colégio Pedro II: mediações entre o ideário republicano e a memória histórica da instituição (1889-1937). 2011. Dissertação (Mestrado em Educação) - Universidade Federal do Rio de Janeiro, Rio de Janeiro, 2011.

MARX, K. A Questão judaica. 1843. Disponível em: <https://www.marxists.org/ português/marx/1843/questaojudaica.htm>. Acesso em: 07 fev. 2016.

MARX, K. O capital: crítica da economia política. Livro I: O processo de produção do capital. Tradução de Rubens Enderle. São Paulo: Boitempo, 2013.

MARX, K.; ENGELS, F. A ideologia alemã. São Paulo: Boitempo, 2007. 
Artigo

doi: $10.20396 /$ rho.v18i2.8651230

OLIVEIRA, R. S. de. A relação entre a história e a imprensa, breve história da imprensa e as origens da imprensa no Brasil (1808-1930). Historiæ, Rio Grande, v. 2, n. 3, p. 125 $142,2011$.

OZELIN, J. R. Periódicos educacionais da escola normal de São Carlos: educação moral, civismo e higiene (1911-1923). 2010. Dissertação (Mestrado em Educação) Universidade Estadual Paulista, Marília, 2010.

PAIVA, G. de. A. G. de. A UNE e os partidos políticos no governo Lula (2003-2010). 2011. Dissertação (Mestrado em Educação) - Universidade Estadual do Oeste do Paraná, Cascavel, 2011.

PIÑEDA, S. S. Hyloea: o feminino na revista dos alunos do Colégio Militar de Porto Alegre (1922-1938). 2003. Dissertação (Mestrado em Educação) - Universidade Federal do Rio Grande do Sul, Porto Alegre, 2003.

SANTOS, V. L. dos. A revista do "Patrocínio": textos e imagens de um periódico escolar dedicado à formação feminina (décadas de 20 e 30, século XX). 2004. Dissertação (Mestrado em Educação) - Universidade de São Paulo, São Paulo, 2004.

SAVIANI, D. Breves considerações sobre fontes para a história da educação. In. LOMBARDI, J. C.; NASCIMENTO, M. I. M. (Org.). Fontes, história e historiografia da educação. Campinas, SP: Autores Associados, 2004. p. 1-12.

SERRA, Á. E. As associações de alunos das escolas normais do Brasil e de Portugal: apropriação e representação (1906-1927). 2010. Tese (Doutorado em Educação) Universidade Estadual Paulista, Marília, 2010.

SILVA, E. C. da. A Configuração do habitus professoral para o aluno-mestre: a escola normal secundária de São Carlos (1911-1923). 2009. Dissertação (Mestrado em Educação) - Universidade Estadual Paulista, Marília, 2009.

SILVA, G. A. A união dos estudantes secundaristas de Patos de Minas (UEP/MG): militância e formação cidadã e político-partidária (1958 a 1971). 2009. Dissertação (Mestrado em Educação) - Universidade Federal de Uberlândia, Uberlândia, 2009.

SIMIAND, F. Método histórico e ciência social. Tradução de José Leonardo do Nascimento. Bauru, SP: Ed. da EDUSC, 2003.

SODRÉ, N. W. História da imprensa no Brasil. 2. ed. Rio de Janeiro: Graal, 1977.

SOUZA, C. Z. V. No mundo das normalistas: as representações da futura professora nas páginas das revistas Instituto e Normalista (1941-1953). 2007. Dissertação (Mestrado em Educação) - Universidade do Estado do Rio de Janeiro, Rio de Janeiro, 2007. 
Artigo

doi: $10.20396 /$ rho.v18i2.8651230

TOLEDO, C. de. A. A. de.; SKALINSKI JUNIOR, O. A imprensa periódica como fonte para a história da educação: teoria e método. Rev. HISTEDBR On-line, Campinas, n. 48, p. 255-268, dez. 2012.

TORRES, C. M. R. Educação e emancipação em Karl Marx e Theodor Adorno. Rev. HISTEDBR On-line, Campinas, v. 17, n. 4 [74], AOP, p. 1266-1282, out./dez. 2017.

VALLE, M. R. do. O diálogo é a violência: movimento estudantil e ditadura militar em 1968. 1997. Dissertação (Mestrado em Educação) - Universidade estadual de Campinas, Campinas, 1997.

\section{VIEIRA, P. M. Psiu! Fermento! Pastoral da Juventude \& imprensa estudantil nos} anos 1980 a 1990. 2014. Dissertação (Mestrado em Educação) - Universidade Federal do Rio Grande do Sul, Porto Alegre, 2014.

ZANLORENZI, C. M. P. A expressão do liberalismo na Revista A Escola (1906-1910) no Paraná. 2014. Tese (Doutorado em Educação) - Universidade Estadual de Ponta Grossa, Ponta Grossa, 2014.

ZANLORENZI, C. M. P. História da educação, fontes e a imprensa. Revista HISTEDBR On-line, Campinas, n. 40, p. 60-71, dez. 2010.

\section{Notas}

${ }^{1}$ Docente do Instituto Federal do Paraná, Campus Irati, PR. Doutoranda do Programa de Pós-Graduação em Educação da UEPG, PR. Pesquisadora do Grupo HISTEDBR - Campos Gerais. E-mail: carla.ramos@ifpr.edu.br

${ }^{2}$ Docente do Programa de Pós-Graduação em Educação da UEPG, PR. Doutora em Educação pela UNICAMP - SP. Coordenadora do Grupo HISTEDBR - Campos Gerais. Professora Produtividade CNPq. E-mail: misabelnasc@gmail.com

${ }^{3}$ Em 1929 surgiu na França a revista Annales e seus maiores expoentes foram Lucien Febvre, Marc Bloch e Fernand Braudel. A intenção desses historiadores era promover uma nova história, se distanciando da linha positivista que dominava a ciência história até o início do século XX.

${ }^{4}$ Os estudos históricos da Escola Metódica, também denominada de Positivista, concentraram-se nos acontecimentos políticos, nas análises cronológicas e na ênfase individual de alguns homens. Sobre esse assunto ver artigo Método Histórico e Ciências Sociais de François Simiand, publicado originalmente em 1903. ${ }^{5} \mathrm{O}$ termo marxiano é empregado nesse estudo, como referência aos conceitos e teorias presentes na produção intelectual-militante de Karl Marx e Friedrich Engels.

${ }^{6}$ A periodização de 1962 e 1963 justifica-se pelo fato do corpus documental, constituído por 11 edições da revista Movimento, ter sido publicado nesse período. Mas como o projeto de doutorado fundamenta-se no materialismo histórico dialético o recorte temporal da pesquisa inicia em 1930, devido às transformações ocorridas com o avanço do capitalismo industrial nessa época, em especial a partir da Era Vargas e se estende até 1964, ano em que ocorre o golpe civil-militar impedindo a continuidade do projeto editorial da revista Movimento.

${ }^{7}$ A noção de Ideologia, utilizado nesse estudo, foi concebida à luz do pensamento de Marx e Engels, em especial os pressupostos teóricos presentes na obra A Ideologia Alemã.

${ }^{8}$ Imprensa de Educação e de Ensino é definida por diversos pesquisadores como imprensa destinada ao público docente, a fim de disseminar projetos e princípios educativos e por meio desta conhecer o pensamento 
pedagógico, o cotidiano educacional e escolar, bem como os discursos educativos dos vários atores deste universo. Sobre essas concepções ver: CATANI, Denice; BASTOS, Maria Helena Camara (Org.). Educação em revista. A imprensa pedagógica e a história da educação. São Paulo: Escrituras, 1997.

${ }^{9}$ Com base na Plataforma Sucupira, foi gerado um arquivo contendo as Instituições de Ensino do Brasil que ofertam Programas de Mestrado e Doutorado Acadêmico e Mestrado Profissional em Educação. Primeiramente, foram excluídas do levantamento as instituições que ofertam os mestrados profissionais, pois os estudos desses programas têm como foco a teoria vinculada à prática educacional. Portanto, procurou centralizar o mapeamento nos programas em educação, cuja, área de concentração do programa fosse Educação, ou que tivessem em sua nomenclatura os termos: História, Sociedade, Política, Cultura e Pensamento Educacional. A partir disso, construiu-se uma planilha contendo as 91 (noventa em uma) instituições brasileiras que possuem mestrado ou mestrado/doutorado em educação e em todas elas foi acessado o banco de dissertações e teses para a realização do estado da arte.

${ }^{10}$ Além das treze produções selecionadas, duas outras foram encontradas, porém não constam no corpus documental desse artigo. Uma delas é a tese de doutorado de Áurea Esteves Serra intitulada As associações de alunos das escolas normais do Brasil e de Portugal: apropriação e representação (1906-1927), por não ser o objeto de investigação atrelado ao campo das ideias. O segundo estudo é a dissertação de Vera Lúcia dos Santos denominada A revista do "Patrocínio": textos e imagens de um periódico escolar dedicado à formação feminina (décadas de 20 e 30 , século XX), por não ter sido encontrada na íntegra e por não ter sido analisada detalhadamente por outros pesquisadores, dificultando assim um estudo mais aprofundado da mesma.

${ }^{11}$ Os periódicos analisados por Valle foram: O Metropolitano (UME do Rio de Janeiro), Jornal do DCE-UFRJ; Grêmio Informa (Faculdade de Filosofia da USP); Jornal da UEE, Revista UNE; Vanguarda no Exílio (Informe do Centro Acadêmico Visconde de Cairu da Faculdade de Ciências Econômicas da USP); e Revisão (Grêmio de Filosofia da USP). Somente o último data-se de 1967, sendo os outros produzidos em 1968.

${ }^{12}$ As referências podem ser encontradas na bibliografia da dissertação de Maria Ribeiro do Valle.

${ }^{13}$ Os periódicos estudantis apresentados por SILVA, G. são: O Sonho, 1934, Alunas da Escola Normal Oficial; O Estudante, 1938, Alunas na Escola Normal Oficial; Alma de Criança, 1940, Alunos do Ginásio Municipal; Lux Jornal, 1945, Alunos do Ginásio Benedito Valadares; A Ozaga, 1953, Órgão de estudantes, sob a gerência de Antônio Mendonça Pinheiro; $O$ Lagoinha, 1955, Alunos do Grupo Escolar "Professor Modesto"; $O$ Sentinela, 1960, Órgão independente de um grupo de estudantes idealistas; O Espelho, 1961, Grêmio Estudantil "Paulo Setúbal", do Colégio Municipal; A Voz da Noite, 1962, Terceiro ano técnico do Colégio Comercial Sylvio de Marco; Mensagem, 1962, Grêmio Estudantil Madre Beatriz do Colégio Nossa Senhora das Graças; Noticiário Estudantil, 1963, Órgão trimestral de imprensa da UEP; Movimento Renovador Cultural, 1965, Academia Literária "Justino Mendes", do Colégio "Dom José Coimbra"; Correio Patense, 1966, Grêmio Literário "Paulo Egídio", do Ginásio Nossa Senhora de Fátima; O Recruta, 1968, Grêmio "Duque de Caxias", do Tiro de Guerra 91; O Realejo, 1969, Alunas da Escola Normal, atual Colégio Estadual "Antônio Dias Maciel".

${ }^{14}$ Para Toledo e Skalinski Junior (2012, p. 263), a materialidade da revista constitui o "[...] tamanho, tipo de papel, qualidade de impressão, formato de suas folhas, uso de cores e imagens.” Além disso, os estudos também se concentram nos conteúdos dos periódicos.

${ }^{15}$ Essa dissertação não foi pesquisada na íntegra, por não estar disponibilizada na plataforma digital do Programa de Pós-Graduação, mas foi referenciada por outros estudos que compõe esse trabalho.

${ }^{16} \mathrm{O}$ conceito marxiano de emancipação está diretamente relacionado ao processo de uma efetiva liberdade onde as lutas de classe, a divisão do trabalho e a propriedade privada não mais existirão. Desse modo, "[...] Emancipar-se não se trata somente de autonomia política, mas, sobretudo voltar-se à natureza humana, eliminando toda e qualquer forma de dominação econômica e suas frações políticas e culturais." (TORRES, 2017, p. 1274).

Submetido em: 14/11/2017

Aprovado em: 14/12/2017

Publicado em: 22/06/2018 